\title{
Exploring Employee Energy Efficiency Awareness in UK Commercial Offices: IT and Small Power
}

\author{
Jessica Morris* and Sonja Oliveira
}

\begin{abstract}
$\underline{\text { Abstract }}$
The purpose of this study is to examine employee awareness and behaviour towards energy efficiency regarding use of IT and small power equipment. Energy efficiency is fundamental to energy policy and a key focus in mitigating climate change in the UK. Energy use is one of the largest controllable overheads in office buildings. IT and small power is one area where inefficient electricity consumption is reported through inappropriate use of small appliance equipment. This study draws on qualitative case study research methods based on two UK cases representing large businesses from differing sectors. The purpose of the study is a survey-based approach to understand employee's awareness and behaviour towards company energy efficiency and office IT and small appliance equipment. This study highlights a number of existing issues regarding employee awareness and energy efficiency including communication, awareness and financial costing. However, it also identified a new contribution; a relationship between the type of work a business undertakes (discipline) and perceived importance /assumed responsibility (employees' attitudes and behaviours) towards energy efficiency in a commercial office environment. The implications of this study are threefold. Firstly, the research identifies employees' perceived importance and assumed responsibility as an area overlooked to which could be contributed to further. Secondly, the analysis enables a novel understanding of the implications of disciplinary affiliation on employee behaviour. Thirdly, there are implications for energy policy in the UK and more broadly in the international commercial office sector which need to be communicated more effectively to employees to bridge the energy efficiency implementation gap.
\end{abstract}

Keywords: commercial offices, behaviour, energy efficiency, employee awareness, small power 


\section{$\underline{\text { Introduction }}$}

Energy consumption reduction is called upon across UK business facilities in order to mitigate the rising impacts of climate change. Business facilities such as office buildings rely on a range of electrical equipment on a day to day basis (Carbon Trust, 2005b). However, it is not always appreciated how much electrical equipment can cost a company (Carbon Trust, 2005b). The need for businesses to assess their current office energy use and seek ways to significantly improve their energy efficiency and energy cost is increasing (Pellegrini-Masini and Leishman, 2011).

The implementation and effectiveness of energy efficient measures within a commercial office environment is reported as a key to the success of improving a business' energy efficiency (DECC, 2012; Westminster Sustainable Business Forum, 2013). Office electrical equipment can be responsible for up to $30 \%$ of total energy consumption. Using equipment more efficiently is suggested to enable a difference to energy use and spending (Npower, 2010).

Individual IT equipment and small appliances is an area where wasteful electricity consumption can often occur through the inefficient use. Typically, desktop and associated IT equipment such as computers, printers, modems and fax machines average about $160 \mathrm{~W}$ per work location commercial offices (BRECSU, 2000). According to Bray (2006), employee usage patterns relating to IT equipment and small power appliance use are a more important factor in determining energy consumption than the energy efficiency ratings of the equipment itself. In addition, out of hours usage is a common issue which needs further investigation by exploring small power behaviour of office workers when leaving at the end of the working day (Bray, 2006).

The purpose of this survey-based approach paper is to examine employee awareness and behaviour regarding energy efficiency implementation in commercial office buildings in the UK, with a focus on IT and small power equipment. The IT and small power equipment which are included as part of this study are laptops, desktop computers, printers, teleconference equipment, fax machines, kettles and microwaves. The following sections discuss key literature on the topic followed by a section on research methods. This is followed by a discussion of key findings, discussion and conclusion outlining key contributions and implications.

\section{Energy efficiency and UK business employee awareness}

Pérez-Lombard, Ortiz and Velázquez (2013) state that the term 'efficiency' is widely used in different fields including engineering, economy, sociology and medicine with different meanings, often as a qualitative attribute, semantically linked to other terms such as efficacy, effectiveness, savings and performance. Energy efficiency, generally, refers to using less energy (i.e. savings) to produce the same amount of services or useful output (i.e. effectiveness/performance) (Patterson, 1996). Businesses are suggested to play a key role in improving energy efficiency within the UK (DECC, 2012). The UK government has in place significant legislation, schemes and policy in order to guide UK businesses, both SME's (small and medium-sized enterprises) and large businesses (DECC, 2012). 
One of the ways for businesses to reduce their carbon footprint is to minimize energy waste. Energy is one of the largest controllable cost overheads in office buildings which means there are numerous opportunities to make savings - for example through control of office equipment. Savings can be both in terms of cost savings and energy savings (Carbon Trust, 2005a). Some of the benefits businesses can gain by controlling energy, in addition to saving money, is the improvement of working conditions which can increase staff productivity (Carbon Trust, 2005b).

Npower (2010) state that in some companies, office equipment can be responsible for up to $30 \%$ of total energy consumption. Using IT and small power equipment more efficiently can therefore make a difference to energy use and spend (Npower, 2010). IT and small power is one area where wasteful electricity consumption can often occur through the inefficient use of small power equipment and appliances, representing a significant percentage of electricity consumption (BRECSU, 2000). According to Bray (2006), employee usage patterns relating to IT and small power equipment are a much more significant factor in determining energy consumption than the energy efficiency ratings of the equipment itself. Furthermore, Bray (2006) suggests that out of hours usage is a common issue which should be further investigated by exploring small power behaviour of office workers when leaving at the end of the working day. A study by Fuertes and Schiavin (2014) analysed plug load energy in an office environment which illustrated a firm misunderstanding about after-hours plug load energy use in office buildings - $17 \%$ of the group assumed that plug load energy intensity would drop to $0 \%$ after hours.

Tetlow (et al., 2014) suggests that many offices (both public and private) in the UK are assumed to implement staff engagement campaigns to encourage people to turn off their computers when not required. These are traditionally designed to focus on giving information to employees about inefficient behaviour.

The filtering down from management to employees of energy efficiency information within a business is proposed to be the most defying part of incorporating more energy efficient practices in studies by EscriváEscrivá (2011) in Spain and Abeelen, Harmsen and Worrell (2013) in the Netherlands.

Escrivá-Escrivá (2011) emphasises that greater communication should be established between users (employees occupying the building) and the building manager in a study on basic actions to improve energy efficiency in commercial buildings in Valencia, Spain. Lack of communication, either no communication or poor communication, is a common theme in several studies on energy efficiency implementation and effectiveness (Roussac, de Dear and Hyde, 2011; Haines III et al., 2011; Dumitru et al., 2016; Lo, Peters and Kok, 2012; Law, Hills and Hau, 2015). Studies that commonly discuss communication also highlight the role of employees, training, staff initiative and responsibility as issues of energy efficiency implementation.

Employees usage behaviour has been investigated by Masoso and Grobler (2010) in Botswana, which can be compared to employee usage behaviour in the UK. They studied the impact of poor occupant behaviour on energy consumption during non-occupied hours' in office buildings. In their study of five office buildings in Botswana (Southern Africa), Masoso and Grobler (2010) found that more energy was used out of working hours' $(56 \%)$ than during working hours' $(44 \%)$. This was partly as a result of employees 
leaving small power appliances on at the end of the day. Out of work hours' energy usage of 56\% illustrates a large amount of energy being used when it shouldn't be. This percentage could easily be reduced by behavioural changes such as switching items off when employees leave at the end of the day (European Environment Agency, 2013). Issues regarding out of hours usage can also be clarified by investigating purely small power plug load patterns when leaving at the end of the working day (Bennet and O'Brien, 2017: Burak Gunay et al., 2016).

Menezes et al. (2013) investigated the energy consumption and usage profiles of desktop and laptop computers in a UK office building. Their results showed that desktop users were more likely to leave computers on outside typical working hours' than laptop users, and that desktops have a higher probability of being on continuously throughout the working day. An area that could be studied further is to investigate employee's IT equipment activity when they leave the office at the end of the day and whether this can be related to their level of awareness or knowledge of office/company energy efficiency.

\section{The role of employees in implementing energy efficiency in office buildings}

Employees affect total energy use of a business directly through their day-to-day behaviours (Lo, Peters and Kok, 2012). Lo, Peters and Kok (2012) report how there is evidence that substantial energy consumption reductions by means of behavioural measures alone are feasible (Dietz et al., 2009).

Research by Pellegrini-Masini and Leishman (2011) into employees' values in the uptake of energy efficiency in office buildings mentioned some degree of pressure by employees in addressing issues of energy efficiency and sustainability in their offices. The paper presents a theoretical framework to explain environmental decision making in firms drawing from sixteen semi-structured individual and group interviews with office market stakeholders in London, Glasgow and Edinburgh. Some respondents referred to the introduction of 'environmental/energy champions' where staff had taken personal involvement in getting involved in energy saving and running ideas and thoughts through committees that are run (Abrahamse and Steg, 2013). In some cases, the interest and involvement in energy saving had come from personal choice of staff, which then developed into a bigger scheme and implemented across other businesses.

A report published by the Association for the Conservation of Energy UK (Wade, Pett \& Ramsay, 2003) suggests that an area of further work is the gathering and dissemination of evidence on the user benefits of energy efficient office working spaces. Wade, Pett and Ramsay (2003) assert that the introduction and implementation of energy efficiency measures, to create an energy efficient office environment, is always seen to be the responsibility of another member of the company chain. Assessing the situation of energy efficiency in offices, identifies communication between stakeholders as the main issue leading to this misperception, suggesting that there is considerable scope to promote interaction that allows all parties to discuss regulation and the best options open to them (Wade, Pett \& Ramsay, 2003; Geiger, Swim, \& Fraser, 2017; Xu et al., 2017). Lack and quality of communication and employee involvement are common themes in energy efficiency implementation and effectiveness (Haines III et al., 2011; Dumitru et al., 2016; Lo, Peters and Kok, 2012; Law, Hills and Hau, 2015). Employee involvement in improving energy efficiency is "crucial" to encouraging behaviour change (Rowney, 2015). 


\section{Behaviour and Motivation}

There is a growing body of evidence in academic literature which demonstrates that there is potential for energy savings due to measures targeting behaviour change (European Environment Agency, 2013). Based on studies of energy efficiency in offices, behaviour and motivation are key elements. Essential to achieving behaviour change is the embedding of knowledge in the general population of both the importance of improving energy efficiency and how to do it (Lo, Peters and Kok, 2012; Menezes et al., 2012). Without that cultural shift, bottom up approaches to energy-efficient improvements will only happen on a sporadic basis. Employee involvement in improvements is "crucial" to encouraging behaviour change as indicated by Rowney (2015).

Originally developed by Ajzen (1991), the Theory of Planned Behaviour (TPB) is one of the most widely applied behavioural models. The TPB suggests that human action is guided by behavioural attitude, subjective norms and perceived behavioural control, and can be predicted provided that the behaviour is intentional (Francis et al., 2004). In essence, the theory claims that, in order to predict whether a person intends to do something, it necessary to know (Ajzen, 1991):

- Whether the person is in favour of doing it ('behavioural attitude')

- How much the person feels the social pressure to do it ('subjective norm')

- Whether the person feels in control of the action in question ('perceived behavioural control').

A widely applied behavioural model, the TPB offers a framework for further research into behavioural attitude and perceived behavioural control (Menezes et al., 2012).

The TPB is an extension of the Theory of Reasoned Action (TRA). The TRA proposed, as a central concept for the prediction of behaviour in any defined social situation, the intention of performing that behaviour. The TPB suggests that behaviours are driven by intentions which themselves are driven by a combination of attitudes, subjective norms, and perceived behaviour control. The theory states that attitude toward behaviour, subjective norms, and perceived behavioural control, together shape an individuals' behavioural intentions and behaviours (Littleford et al., 2014).

A central factor in the theory of planned behaviour is the individual's intention to perform a given behaviour. Intentions are assumed to capture the motivational factors that influence a behaviour; they are indications of how hard people are willing to try, of how much of an effort they are planning to exert, in order to perform the behaviour (Ajzen, 1991). As a general rule, the stronger the intention to engage in a behaviour, the more likely should be its performance.

One application of the theory of planned behaviour is in the field of environmental psychology. Generally speaking, actions that are environmentally friendly carry a positive normative belief (Koger and Winter, 2010). That is to say, sustainable behaviours are widely promoted as positive behaviours. However, although there may be a behavioural intention to practice such behaviours, perceived behavioural control can be hindered by constraints such as a belief that one's behaviour will not have any impact (Stern, 2005). For example, if one intends to behave in an environmentally responsible way but there is a lack of accessible efficiency infrastructure, perceived behavioural control is low, and constraints are high, so the behaviour 
may not occur. Applying the theory of planned behaviour in these situations helps explain contradictions between sustainable attitudes and unsustainable behaviour.

Lo et al. (2014) examine if organizational contextual variability independently predicted office energysaving behaviours over and above TPB variables and self-reported habit in the Netherlands. The results indicated that intention was the strongest direct predictor of the behaviours printing smaller and not printing e-mails, whereas habit was the strongest predictor of the behaviours switching off lights and switching off monitors. The findings suggest that the relative importance of cognitive factors and habit varies between office energy-saving behaviours and to a lesser extent between organizations (Lo et al., 2014). This study illustrates that employee awareness and behaviour is subjective to the type of energy saving method e.g. printing less, switching off lights, switching off monitors.

This study uses the TPB as a theoretical framework in designing the survey questions and analysis of the results through categorisation to understand the behavioural attitude and perceived behavioural control of the study's participants.

\section{$\underline{\text { Research Methods and Design }}$}

The objective of the research was to explore energy efficiency of IT and small power equipment in office buildings in relation to UK business employee awareness, the role of employees and understanding employee's behaviour and motivation. The research for this study required examining a variety of opinions to potentially illustrate a pattern or theme across different samples. This type of research is suited to the qualitative research method of comparative case study as advocated by Yin (2003), which was chosen for this study.

Yin (2003) describes case study methodology as a means of empirical research appropriate for exploring the how and why of contemporary phenomena within a real-life context. Comparative case study approaches are recognised as providing a means to examine a multiplicity of perspectives to illustrate a social entity or pattern across cases (Hakim, 2000). Techniques applied to case study methods have been described by Yin (2003) as including use of multiple sources of information, addressing and explaining variations when using multiple case studies.

The case study strategy is suited to this research, where the focus is on human interpretations and attributed meanings (Oliver, 2004). It is precisely the relationship between the phenomenon (i.e. employee awareness on energy efficiency) and the cultural context that was investigated in this study. Although the hallmark of qualitative interpretive methods, case studies should not be thought of as synonymous with or as exclusively qualitative research.

However, research design using multiple case studies predominantly uses qualitative tools and techniques for data collection and analysis (Darke et al., 1998). As the objectives of this study were to investigate 
differences in employee awareness and attitudes towards energy efficiency, the multiple case study approach focusing on comparable organisations in the UK through qualitative techniques was appropriate.

\section{Data Collection}

An online questionnaire was considered most practical as it could discover the information and opinions required in addition to its fast process (Bryman, 2015). Research into studies undertaken in the topic for this research (energy efficiency and commercial office buildings) illustrated a mixture of methods have been used, however predominantly by questionnaire. Categorical and Likert scale in addition to open-ended questions were selected to form the structure of the questionnaire, drawing on both quantitative and qualitative results.

Categorical and Likert scale questionnaires, selected in quantitative studies, are a form of quantitative research and do not include or attract detailed responses as are sought in this research (Redline, 2013). However, Categorical and Likert question structure can be used for some questions in order to gain data such as general respondent information (gender, age, job title, etc.), employees opinion of their extent of energy use and what small power equipment they use (Allen and Seaman, 2007). Open-ended questionnaires are a form of qualitative research, asking open-ended questions in order to understand participant's perspective and behaviour which was required in this research. Data from this method can gain responses from an individual level, and to find out the ways in which people think or feel through descriptive information (Fink, 2003).

Secondary data was collated through documentary research of each case study company. Documentary sources were used to provide background information and an understanding of the company's functions and responsibilities. This included energy policy and corporate responsibility documents, which were reviewed to understand company practice and policy in relation to office energy efficiency and small power items.

\section{Questionnaire design}

\section{Behavioural and attitude consideration in questionnaire design}

Survey (questionnaire) question methods and measuring constructs were taken from the TPB (as discussed in sections above) in order to design the questionnaire with a theoretical framework in mind. Two key TPB analytical dimensions were applied when designing questions including: whether the person is in favour of doing it ('behavioural attitude') and whether the person feels in control of the action in question ('perceived behavioural control'). That is to understand how important employees perceive their behaviour to be in relation to office energy efficiency and whether they believe they, or someone else, are responsible for the energy efficiency of certain types of individual and or shared equipment within the office.

The online questionnaire was split into four sections; general information, company energy efficiency, individual office equipment and communal office appliances/equipment. The first section, general information, was designed to gain a better understanding of the person completing the questionnaire. This includes questions in categorical and linkerLikert scale format on gender, age group, job title, how long 
they have worked for the company and whether their job is part time or full time. By asking these generic questions, comparisons or distinctions were made from the results. For example, if the degree of knowledge is associated with the length of time worked in the business or their job level. Or if there was a connection between full time/part time employees and small power behaviour.

The second section sought to understand employee's knowledge of who is responsible for energy efficiency in their off and if an energy policy is in place. Employees were also asked to what extent they believed their behaviour was critical to office energy efficiency. If employees believed their behaviour makes little difference, it could affect their behaviour in regards to being energy efficient in the office. The final questions in this section investigated employee's awareness of energy efficiency measures the company has in place around the office and the importance of all levels of employees being made aware of what they can do to use IT and small power items more efficiently.

The third section asks to what extent the employee believes they are energy conscious and distinguishes what type of small power equipment (desktop, laptop, laptop and monitor or both) they use and their shutdown procedures of such equipment when they leave the office at the end of the working day. Comparisons and distinctions are then made between these two questions alone as some employees may consider themselves to be energy conscious however, their shutdown procedure of IT equipment can have the opposite effect.

The fourth and final section is based on communal appliances/equipment (printers, teleconference equipment, kettles, microwaves). Questions were selected that gained an understanding of who the employee believes is responsible for turning off communal equipment and their knowledge to whether communal items are actually left on or switched off. The results from these questions helped to clarify which person to whom the employee allocates responsibility for the efficiency of all other small power items in their office.

\section{Sampling}

Purposive sampling was applied in order to select two businesses, and an office location for each business. Random sampling of participants to complete the survey was then used in order to gain a mixture of responses from employees working in that office (Teddlie and Yu, 2007; Mason, 2002).

Two large businesses (500+ employees) and two office locations were selected to contact and distribute the questionnaire. Participants for the questionnaires were required to be employees whose work was predominantly based within a commercial office environment. Therefore, two businesses were selected which had employees that fitted these criteria. These were an office of a multinational brewing and beverage company (referred to as company $\mathrm{X}$ ) in Luton and an office of a multinational environmental consultants (referred to as company Y) in Bristol. An environmentally focused company was intentionally selected to understand if employee awareness regarding energy efficiency differed to a non-environmentally focused company. Both of these locations employees were permanently based in that particular office environment. Information about each company can be seen in Table 1 below. 
$<<$ Insert Table 1 here $>>$

Company $\mathrm{X}$ was founded as part of a merger with other brewing businesses dating as far back as 1742 , with their global headquarters in Leuven, Belgium. Their main area of business are beverages and brewing on a multinational scale. Company Y's head office is based in Helsby, UK. Their main areas of business are sustainability, ecological and environmental services, environmental impact assessment and site investigations.

Table 2 below illustrates specifically what documentary evidence was also used to gain background information about each company and understand each companies aims and policy on environmental and energy efficiency issues.

$<<$ Insert Table 2 here $>>$

Company X's annual report highlights their environmental stewardship which includes environmental initiatives including 'shock the drought', 'World Environmental Day' and 'Green logistics'. In addition, Company X's 2017 Environmental goals include reducing production energy use and greenhouse gas emissions on a global scale. However, there is a lack of policy/documentary information about their employee operations and actions regarding environmental and energy efficiency initiatives and goals.

Company Y's corporate responsibility statement is very environmentally focused, underlining their commitment to environmental certification, communication and energy usage reduction throughout their operations. Company Y's sustainability statement specifically highlights the company's commitment to reducing their UK office emissions by $5 \%$.

\section{Sampling strategy}

The online questionnaire was produced and sent out to two company offices in Luton and Bristol. A pragmatic approach for data collection was taken in that it aimed to gain as many responses as possible (Mason, 2002). The questionnaire was sent to a company representative at each company who distributed to 50-60 employees. As the questionnaires were distributed to the employees at Company X and Company $\mathrm{Y}$, the participants were informed that they are invited to participate in this research project because they are an employee working in a commercial office environment on a day-to-day basis and that their participation in this research study was voluntary. It was also conveyed to the employees that they may choose not to participate and if they did decide to participate in this research survey, they may withdraw at any time.

At the start if the questionnaire, the participants were informed that the purpose of this research project was to explore employee knowledge of company energy efficiency and IT \& small power behaviours and attitudes in commercial offices. It also defined that IT \& small power equipment/appliances refers to electrical items such as PCs, laptops, printers, photocopiers, teleconference equipment, kettles, microwaves. 
Finally, the potential participants were made aware that the procedure of filling in this online survey would take approximately 5-10 minutes and the responses would be anonymous and confidential and would not collect identifying information such as their name, email address or any other personal details.

In total, from both companies, 52 responses were received - 27 from Company $\mathrm{X}$ and 25 from Company Y. However, qualitative samples are inevitably small because in collecting rich insight these data will be bulky, however there are no rules for sample size in qualitative research (Emmel, 2013). The total 52 responses received demonstrated credibility of responses from various departments in each company

\section{Data Analysis}

The responses collected from the questionnaire have been analysed through content thematic analysis as advocated by Fink (2003). Drisko and Maschi (2015) and Fink (2003) describe content thematic analysis as a system of collecting and understanding data that investigates perceptions and experiences of individuals to describe or explain knowledge, attitudes and behaviour. The elements that were considered when analysing the questionnaire content were the primary concern of the respondent, the themes hidden in the responses and the motivation of the respondent as to their answers.

The focus of qualitative content analysis is identifying categories or themes that both summarize the content found in the questionnaire results and highlight key content. To achieve this goal, the meaning of content may be interrogated and expanded (Drisko and Maschi, 2015). To effectively analyse this information, the topics covered in the questionnaire formed the subheadings for discussion of the themes identified in the responses and conclusions of the data. The trends identified in the transcripts are linked to the objectives of the research project and also related back to the literature studied in regards to key approaches identified to the topic (Silverman, 2006). The documentary policy research (secondary data) was analysed in the same manner and cross linked to the questionnaire results to identify any similarities or discrepancies between practice and policy.

In the first stage of analysis the responses from the questionnaire and company policy evidence were analysed, looking for common themes. Initial descriptive analysis, explaining what was said in the responses, was undertaken. From this, several themes were highlighted which were taken from each question. The themes included energy efficiency measures, company policy, collective responsibility, participation and accountability, importance of energy efficiency and awareness throughout the company hierarchy. Finally, analytical re-reading looked for how the themes could be grouped under thematic categories based on the tow TPB dimensions discussed above. The three categories highlighted from the initial analysis were; 'Lack of perceived awareness', 'Assumed responsibility' and 'Perceived importance'. These were formed based on the three key elements stated by Azjen (1991) to understand a person's intentions. Table 3 highlights the most important initial findings from the survey responses.

$<<$ Insert Table 3 here $>>$ 


\section{Findings}

\section{Lack of perceived awareness}

The lack of perceived awareness category includes employee's knowledge of who the energy (or environmental) manager is in their company, their knowledge of company energy policy, energy efficiency measures within their office environment and employee engagement according to company energy policy/documents. Table 4 illustrates the key points and issues associated with lack of perceived awareness of energy efficiency from the questionnaire responses and company policy evidence.

$<<$ Insert Table 4 here $>>$

Two-thirds of the sampled employees from both companies did not know the person that is responsible for energy management/efficiency in the office they worked in. In addition, even more employees from both companies were unaware of any company energy policy. One of the participants Company Y stated they are not aware as "there is not a lot of guidance surrounding it [energy management/efficiency]". Nearly three quarters of respondents from both companies were unaware of any Energy Efficiency Measures (EEMs) within the office they worked in. The employees that were aware in Company X had been informed mainly from either a company newsletter or by talking to colleagues. In their environmental policy, Company X claim that they believe it is important to keep our employees challenged and inspired. To gauge this they run a global employee engagement survey each year to gather feedback on issues such as communication and senior leadership.

In Company Y, the few employees that were aware of EEMs were informed likewise through speaking to colleagues but also via office posters, stickers or factsheets. Again, this highlights the issue of communication. Company Y suggest that they communicate the needs and requirements of their Environmental Management System (EMS), involving our employees through regular meetings with the office CR representatives.

\section{Assumed responsibility}

The assumed responsibility category includes whether employees believed their behaviour was critical to office energy efficiency, communal and individual small power control and responsibility according to company energy policy/documents. Table 5 illustrates the key points and issues associated with assumed responsibility of energy efficiency within the office from the questionnaire responses and company policy evidence.

\section{$<<$ Insert Table 5 here $>>$}

From Company X, over two thirds of respondents believed that their behaviour was critical to office energy efficiency, in particular thinking of the collective importance. One Company X respondent said;

"Energy consumption in the office and at home is directly influenced by every individual's behaviour. Simply switching off screens, projectors and lighting can have a significant impact on 
energy efficiency and costs. It is very important that every employee understands the impact and results of their actions and responds accordingly".

The remaining respondents from Company X suggested either that it wasn't very important or that they hadn't really thought about it. In their policy, Company X commit to encourage employee participation and individual accountability for environmental actions in improving the resource-efficiency of the company's operations.

On the other hand, from Company Y just over half of people believed that their behaviour was critical, some in particular suggesting that each person has a responsibility and how they believed their "behaviour individually isn't that critical, but overall, with everyone else, it is critical”. Company Y participants also highlighted they thought their actions only made a small contribution/insignificant contribution. Company Y claim in their Sustainability Policy that they have begun a collective effort towards limiting their carbon footprint by setting a target for reducing their UK office emissions.

Nearly three quarters of employees at Company $\mathrm{X}$ believed that it was their responsibility for switching off communal IT and small equipment, with the remaining suggesting it was either someone else in their team, cleaning staff or everyone's responsibility. Whereas with Company Y, just half of employees believed it was their responsibility. Just under half of employees also suggested other, specifying the responsibility was with either the last users, the IT manager or, similarly to Company X, everyone's responsibility. Nearly half of respondents from both companies indicated that they were unsure as to whether communal IT and small power items were left switched on or turned off. Of the remaining, the majority of Company X stated communal items were turned off, whereas at Company Y the majority stated they were left switched on.

\section{Perceived importance}

Perceived importance is the most substantial of the three categories as this had the most noteworthy responses from the questionnaire. The perceived importance category included the efficient use of IT and small power, all company hierarchy to be made aware, whether employees considered themselves energy conscious and the company's focus in regards to energy efficiency according to company energy policy/documents. Table 6 illustrates the key points and issues associated with perceived importance of energy efficiency from the questionnaire responses and company policy evidence.

$<<$ Insert Table 6 here $>>$

When asked about the importance of efficient use of IT and small power to their company, respondents from both Company $\mathrm{X}$ and $\mathrm{Y}$ answered with one or two similar themes. Some of the responses from Company X were:

"IT and small power equipment usage within the company is very high and therefore the efficient use of this equipment contributes significantly to energy consumption. The company [Company $\mathrm{X}]$ are aware of this impact and encourage employees to reduce waste as much as possible” 
"I think IT in particular is important as our company is heavily based on IT use so definitely in terms of reducing energy costs",

"Keeping costs in control ensures we meet business targets"

"Important as we can achieve business targets by keeping costs like this as low as possible"

Employees from Company X predominantly thought efficient use of small power was important for keeping business costs down and to meet business targets. Company $\mathrm{X}$ has environmental policies for both the UK and globally. The UK environment policy focuses on three main areas; reducing water use, reducing energy use and emissions, and reducing waste and improving packaging. Company $\mathrm{X}$ state they are committed to conserving energy and reducing our $\mathrm{CO}_{2}$ emissions. And, that energy conservation has been a strategic focus at the company for many years, in particular with the unpredictable cost of energy and the increased focus on climate change. In their global environmental responsibility policy, Company X reiterate their commitment to conserving and reducing their energy. In addition, stating how their comprehensive approach to managing this critical resource [energy] saves money, curtains GHGs, mitigates business risks, and ultimately, enhances cost effectiveness.

On the other hand, Company Y respondents reflected that it was important for their environmental impact on a cumulative /company-wide basis in addition to reducing costs and achieving business targets:

"Our company is very heavily reliant on IT and with us being an environmental consultant, efficient use of IT is important for our company in order to reduce our environmental impact”

"As an environmental company I think it is important for us to use equipment as efficiently as possible to reduce our impact on the environment”

"As we use a lot of IT equipment, it is important for productivity and reaching business targets"

"I think overall efficient use is important as it will keep costs down for the company"

Other responses that commonly appeared from both companies were the importance to business targets (productivity) and the belief that it was not important. Company Y's Corporate Responsibility Statement is predominately focused on their commitment and accountabilities, environmentally and socially. Some of these include;

- $\quad$ Promoting the concept of sustainability.

- Minimising the environmental impact of all aspects of their business operations.

- Measuring their energy use and carbon emissions.

- Communicating their environmental management system and CR policy to all.

- Supporting the communities in which they operate through charitable donations, community engagement and environmental education.

In addition, Company $\mathrm{Y}$ has a statement on their responsibility to sustainability. As part of this they state that they aim to demonstrate their endeavour to work in the most sustainable way they can by limiting their carbon footprint, implementing a company-wide recycling programme, fostering the use of alternative modes of transport and embedding a culture of water conservation. In the 'Carbon Foot printing' section of their sustainability policy, Company $\mathrm{Y}$ suggest that the threat of climate change is the most serious 
environmental issue facing humanity. Stating that as a responsible member of the community, the company is doing their part to disclose and reduce carbon dioxide emissions. Their Corporate Responsibility (CR) Policy Statement also indicates that Company Y are committed to communicating the requirements and needs of their environmental management systems and CR policy to all. And 'Involving the company's employees through regular meetings with the office CR representatives".

Nearly all employees in both company cases believed it was very important for all levels and grades of employees and management to be made aware of ways they can use IT and small power equipment more efficiently. The reason of importance was mainly so that everyone in the company was aware and not just certain job grades in order to make a big difference. But also that this should be done through training so that all employees can contribute as much as possible. A respondent from company X stated; "Every employee in the company should be trained and made aware of energy efficiency because is has both short and long term consequences for both the company and the wider world as a whole”. One of the participants from Company $\mathrm{Y}$ implied that making all employee grades aware was "Totally essential otherwise every small saving by those adhering to the requirements is wiped out by those wasting the savings-every little counts!".

Individual small power and IT equipment use were different in both companies. Employees at Company $\mathrm{X}$ predominantly use a laptop whereas employees at Company Y use main a laptop with a PC monitor. Out of hours behaviour illustrated that around two thirds of respondents at Company X fully shutdown their laptops with the majority turning off their chargers as well. However, a third still stated that they left their laptops on standby overnight. At Company Y, around $90 \%$ of respondents specified that they fully shutdown their laptops (again with the majority turning off their chargers as well) and around 90\% turning off their monitors too. The remaining small percentage left their laptops on standby and chargers on overnight. Following on from this, when asked to what extent they agree or disagree in considering themselves energy conscious, the majority in both company cases (between a third and half of respondents) said they agreed with the statement. The rest of the responses were evenly spread with respondents suggesting they strongly agreed, we're undecided or disagreed. Not a single person stated they strongly disagreed in being energy conscious from both Company $\mathrm{X}$ and Company $\mathrm{Y}$.

A relationship between the type of work and perceived importance/assumed responsibility of energy efficiency and environmental impact was highlighted. Company Y's discipline as an environmental company illustrates a strong correlation with the behaviour of its employees towards energy use and environmental impact.

\section{$\underline{\text { Discussion }}$}

Findings in this study extend and contribute to recent research conducted on the effectiveness of energy efficiency implementation across diverse contexts but particularly in commercial office environment. In accordance with recent work by Roussac et al., (2011); Haines III et al., (2011) and Dumitru et al., (2016), analysis in this study similarly observed participants' perceived lack of awareness and communication across the two cases. In addition, responses in relation to whether participants' behaviour was critical reflected recent research arguing that employees affect the energy use of a business through their day-to- 
day behaviour (Lo, Peters and Kok, 2011). Perceived behaviour control found in this study to be hindered by limitations such as employees having the belief that their individual behaviour will not have any impact was also articulated by Stern (2005). Extending Stern's (2005) work, findings in this paper suggest that individual behaviour conveyed through a sense of 'personal responsibility' was found to be important in relation to communal equipment.

It is suggested in this paper that employees also significantly influence energy responsible practices within a business, in particular through their approaches in operating office small power items, contradicting some of the work conducted by Wade et al (2013). Company X, in their policy, state that they are committed to 'encouraging individual accountability for employees' environmental actions. However, the ways through which participants discussed their accountability and the importance this played in the implementation of the company's energy efficiency policy differed across the two cases. Participants from Company X predominantly emphasised financial costs and savings to be of most importance to their company in relation to energy efficiency with their office buildings. Financial costs and savings were perceived to be one of the main drivers and barriers of energy efficiency within commercial office buildings (DECC, 2012; Westminster Sustainable Business Forum, 2013). Findings from the questionnaire and their environmental policy suggest that financial cost is of great importance to Company X. On the other hand, Company Y's questionnaire responses and $\mathrm{CR}$ statement focused on their environmental and social commitment and responsibilities. The focus and enhancement on $\mathrm{CR}$ has become a conventional corporate activity as changing social beliefs on environmental performance has put pressure on businesses to identify their responsibilities towards the environment and the community (Haynes, Murray and Dillard, 2013).

Characteristics of perceived importance of energy efficiency was also discussed differently in each case company. For Company $\mathrm{X}$ this was financial costs and savings, for Company $\mathrm{Y}$ it was environmental impact. Company Y participants stated that being part of an Environmental Consultancy, they perceived reducing their environmental impact was important. As Company Y is an Environmental Consultancy, environmental impact being of most importance regarding energy efficiency coincided with the nature of the business itself. A potential relationship between the type of work as an environmental consultancy and the perceived importance and priority of environmental impact/responsibility was identified. It is therefore conceivable that the discipline of an environmental business has a relationship with its employee's environmental attitudes and behaviour, in addition to its policy. This relationship was not identified in the literature and offers a new contribution to research on the topic of employee behaviour and energy efficiency within commercial office buildings in the UK.

Both companies' employees emphasised the importance for all levels and grades of employees to be educated on ways they can be more energy efficient in the office, some respondents suggesting to be done through training. The 'behavioural attitude' element of the TPB is demonstrated here as employees emphasised the willingness to be better educated on improving energy efficiency within their office environment. Environmental education and awareness training was identified in the literature as a potential method in helping to encourage the transition to a greener corporate culture (Law, Hills and Hau, 2015). The importance of the filtering down of information on energy efficiency was seen as a defying part of 
incorporating energy efficient practices within a business, which was also confirmed in other studies in the literature (Vine, 2008; Escrivá-Escrivá, 2011).

Responses from Company Y show that employees of the environmental consultancy illustrate positive behavioural attitude regarding out of hours usage of small power items (Littleford et al., 2014; Ajzen, 1991; Francis et al., 2004). This again highlights that Company Y's nature of work is reflected in the behaviour of it employees and also contributes to understand employee's behaviour through the TPB element of 'subjective norm'.

As a whole, the results help to understand employee's attitudes and intentions towards energy efficiency in their office environment through the TPB three key elements of 'behavioural attitude', 'subjective norm' and 'perceived behavioural control' to understanding a person's intentions to do something.

\section{Conclusion}

The overall aim of this research was to examine employee awareness and behaviours regarding energy efficiency integration in commercial office buildings in the UK with a focus on IT and small power. Firstly, the research identifies employees' perceived importance and assumed responsibility as an area overlooked to which could be contributed to further. This results of this study has provided a contribution of knowledge in relation to perceived importance; the relationship between type of work (discipline) and perceived importance/assumed responsibility (employee behaviour). The research suggested that being an environmental consultant, Company Y's employees had more regard for their environmental attitudes and behaviours.

Secondly, the analysis enables a novel understanding of the implications of disciplinary affiliation on employee behaviour. Enhancing corporate responsibility has become more apparent as changing social beliefs on environmental performance has put pressure on businesses to identify their responsibilities towards the environment and the community. In addition, employees emphasised the willingness to be better educated on improving energy efficiency within their office environment.

Thirdly, the findings of the research extend a number of existing issues discovered in the literature surrounding energy efficiency and employee awareness in commercial office buildings, one of the main issues being communication. There are implications for energy and environmental policy in the UK and more broadly in the international commercial office sector which need to be communicated more effectively to employees to bridge the energy efficiency implementation gap, for example through newsletters or employee training.

This study experienced some limitations. The comparatively small sample size limit the extent to which the finding of the research can be generalised. The issue of sampling was identified before the research was undertaken, however there was no guarantee as to the minimum amount of responses that could be achieved. In addition, the research methods used were limited due to practical issues. For example, interviews to conduct more in-depth research were not completed in addition to the questionnaire because 
of time and financial constraints. In spite of these limitations, the study has produced some potentially useful findings that could provide the basis for further research beyond the UK.

The findings from this study extend research by Roussac et al. (2011), Haines et al. (2011), Lo et al. (2012), Law et al. (2015) and others regarding lack of employee awareness and communication regarding energy efficiency in commercial office buildings. However, it has contributed knowledge that has scope to be investigated further.

In extension of this research, it is recommended that the contribution of knowledge from this study is investigated further. The relationship between type of work and perceived importance/assumed responsibility should be explored even more, and on a bigger scale, studying purely environmental businesses. Using more case studies, increasing the sample size, and additional research methods such as interviews to conduct more in-depth research and further clarify this relationship. This study was UK based, it is therefore suggested that, in addition, further study is undertaken on an international level to gain a broader and more thorough view of this contribution. Further research into this area could reveal if this is a running theme in environmental related companies. If further research provides evidence that environmental businesses are or are not energy efficiency conscious and driven themselves, then this could affect the attitudes of other business in the UK and internationally towards their energy efficiency and environmental efforts. Environmental related businesses demonstrating energy consciousness could then be used by governments as a spokesperson for influencing other businesses to improve their energy efficiency.

\section{$\underline{\text { References }}$}

Abeelen, C., Harmsen, R. and Worrell, E. (2013) Implementation of energy efficiency projects by Dutch Industry. Energy Policy [online]. 63, pp. 408-418.

Abranhamse, W. and Steg, L. (2013) Social influence approaches to encourage resource conservation: A meta-analysis. Global Environmental Change [online]. 23, pp. 1773-1785.

Ajzen, I. (1991) The Theory of Planned Behaviour. Organizational Behaviour and Human Decision Process [online]. 50, pp. 179-211.

Allen, I.E. and Seaman, C.A. (2007) Likert scales and data analyses. Quality progress [online]. 40(7), pp.64.

Bennet, I.E and O’Brien, W (2017) Office building plug and light loads: Comparison of a multi-tenant office tower to conventional assumptions. Energy and Buildings [online]. 153, pp.461-475.

Bray, M. (2006). Review of Computer Energy Consumption and Potential Savings. Hereford: Dragon Systems Software Limited. https://www.dssw.co.uk/research/computer_energy_consumption.html 
BRECSU (2000) Energy Consumption Guide 19: energy use in offices. Watford: Building Research Energy Conservation Support Unit.

Bryman, A. (2015) Social research methods. 5th edition. Oxford: Oxford University Press.

Burak Gunay, H., O’Brien, W., Beausoleil-Morrison, I. and Gilani, S. (2016) Modeling plug-in equipment load patterns in private office spaces. Energy and Buildings [online]. 121, pp.234-249.

Carbon Trust (2005a) Creating an Awareness Campaign: Energy Awareness in your business [online]. https://www.carbontrust.com/media/601934/ctg056-creating-an-awareness-campaign.pdf

Carbon Trust (2005b) The UK Climate Change Programme: Potential Evolution for Business and the Public Sector. London: The Carbon Trust.

Darke, P., Shanks, G. and Broadbent, M. (1998) Successfully Completing Case Study Research: Combining Rigour, Relevance and Pragmatism. Information Systems Journal [online]. 8, pp. $273-289$.

DECC (2012) The Energy Efficiency Strategy: The Energy Efficiency Opportunity in the UK [online]. London: Department of Energy and Climate Change.

https://www.gov.uk/government/uploads/system/uploads/attachment_data/file/65602/6927-energyefficiency-strategy--the-energy-efficiency.pdf

Dietz, T., Gardner, G.T., Gilligan, J., Stern, P.C., and Vandenbergh, M.P. (2009) Household actions can provide a behavioral wedge to rapidly reduce US carbon emissions. Proceedings of the National Academy of Sciences of the United States of America [online]. 106(44), pp. 18452-18456.

Drisko, J. \& Maschi, T. (2015) Content Analysis. Oxford University Press, New York.

Dumitru, A., De Gregorio, E., Bonnes, M., Bonaiuto, M., Carrus, G., Garcia-Mira, R. and Maricchiolo, F. (2016) Low carbon energy behaviours in the workplace: A qualitative study in Italy and Spain. Energy Research \& Social Science [online]. 13, pp49-59.

Emmel, N. (2013) Sampling and choosing cases in qualitative research: a realist approach. Los Angeles: SAGE.

Escrivá- Escrivá, G. (2011) Basic actions to improve energy efficiency in commercial buildings in operation. Energy and Buildings [online]. 43 (11), pp. 3106-3111.

European Environment Agency (2013) Achieving energy efficiency through behaviour change: what does it take?. http://www.eea.europa.eu/publications/achieving-energy-efficiency-through-behaviour

Fink, A. (2003) The survey handbook. 2nd edition. California: Sage Publications. 
Francis, J., Eccles, M., Johnston, M., Walker, A., Grimshaw, Foy, R., Kaner, E., Smith, L. and Bonetti, D. (2004) Constructing Questionnaires Based on The Theory of Planned Behaviour - A Manual for Health Services Researchers [online]. Newcastle upon Tyne: Centre for Health Services Research, University of Newcastle.

http://openaccess.city.ac.uk/1735/1/TPB\%20Manual\%20FINAL\%20May2004.pdf

Fuertes, G and Schiavin, S (2014) Plug load energy analysis: The role of plug loads in LEED certification and energy modelling. Energy and Buildings [online]. 76, pp. 328-335.

Geiger, N., Swim J.K., Fraser, J. (2017). Creating a climate for change: Interventions, efficacy and public discussion about climate change. Journal of Environmental Psychology [online]. 51, pp. 104-116.

Haines III, V.Y., Rousseau, V., Brotheridge, C.M. and Saint-Onge, E. (2011) A qualitative investigation of employee business awareness. Personnel Review [online]. 41(1), pp.73-87.

Hakim, C. (2000) Research design: successful designs for social and economic research. 2nd Edition. London: Routledge.

Haynes, K., Murray, A. and Dillard, J.F. (2013) Corporate Social Responsibility: a research handbook. London: Routledge.

Koger, S. and Winter, D. N. N. (2010) The Psychology of Environmental Problems [online]. New York: Psychology Press.

Law, M.S.L., Hills, P., and Hau, B.C.H. (2015) Engaging employees in sustainable development - a case study of environmental education and awareness training in Hong Kong. Business Strategy and the Environment [online].

Littleford, C., Ryley, T.J. and Firth, S.K. (2014) Context, control and the spill over of energy use behaviours between office and home settings. Journal of Environmental Psychology [online]. 40, pp.157166.

Lo, S. H., Peters, G.-J. Y. and Kok, G. (2012) Energy-Related Behaviours in Office Buildings: A Qualitative Study on Individual and Organisational Determinants. Applied Psychology [online]. 61, pp. $227-249$.

Lo, S.H., Peters, G.Y., van Breukelen, Gerard J. P \& Kok, G. (2014) Only reasoned action? An interorganiational study of energy-saving behaviours in office buildings. Energy Efficiency. 7 (5), pp. 761 775 .

Mason, J. (2002) Qualitative researching. 2nd Edition. London: Sage. 
Masoso, O.T. and Grobler, L.J. (2010) The dark side of occupants' behaviour on building energy use. Energy \& Buildings [online]. 42 (2), pp. 173-177.

Menezes, A., Cripps, A., Buswell, R. \& Bouchlaghem, D. (2013). Benchmarking small power energy consumption in office buildings in the United Kingdom: A review of data published in CIBSE Guide F. Building Services Engineering Research \& Technology. 34(1), pp.73-86.

Npower (2010) Practical Energy Efficiency Advice for Businesses.

http://www.npower.com/idc/groups/wcms_content/@wcms/@resi/documents/digitalassets/energy_efficie ncy_guide.pdf

Oliver, G. (2004) Investigating Information Culture: A Comparative Case Study Research Design and Methods. Archival Science [online]. 4(3), pp. 287-314.

Patterson, M.G. (1996) What is energy efficiency?: Concepts, indicators and methodological issues. Energy Policy [online]. 24(5), pp. 377-390.

Pellegrini-Masini, G. and Leishman, C. (2011) The role of corporate reputation and employees' values in the uptake of energy efficiency in office buildings. Energy Policy [online]. 39 (9), pp. 5409-5419.

Pérez-Lombard, L., Ortiz, J. \& Velázquez, D. (2013) Revisiting energy efficiency fundamentals. Energy Efficiency [online]. 6(2), pp. 239-254.

Redline, C. (2013) Clarifying Categorical Concepts in a Web Survey. Public Opinion Quarterly [online]. 77, pp. 89.

Roussac, C., de Dear, R. and Hyde, R. (2011) Quantifying the 'human factor' in office building energy efficiency: a mixed-method approach. Architectural Science Review [online]. 54 (2), pp. 124-131.

Rowney, M. (2015) Driving Energy Efficiency in the Commercial Sector. https://www.tuc.org.uk/sites/default/files/Money_To_BurnTS.pdf

Silverman, D. (2006) Interpreting qualitative data: methods for analysing talk, text and interaction. 3rd Edition. Los Angeles: SAGE.

Stern, P. C. (2005) Understanding individuals' environmentally significant behaviour. Environmental Law Reporter: News and Analysis [online]. 35, pp. 10785-10790.

Teddlie, C. \& Yu, F. (2007) Mixed Methods Sampling: A Typology with Examples. Journal of Mixed Methods Research [online]. 1(1), pp. 77-100. 
Tetlow, R.M., Beaman, C.P., Elmualim, A.A. and Couling, K. (2014) Targeting automatic behaviour to reduce small power electricity consumption in office buildings [online]. University of Reading. http://www.reading.ac.uk:8081/web/FILES/tsbe/Tetlow_TSBE_Conference Paper_2013.pdf

Vine, E. (2008) Strategies and policies for improving energy efficiency programs: Closing the loop between evaluation and implementation. Energy Policy [online]. 36 (10), pp. 3872-3881.

Wade, J., Pett, J. \& Ramsay, L. (2003) Energy Efficiency in Offices: Assessing the Situation [online]. http://www.ukace.org/wp-content/uploads/2012/11/ACE-Research-2003-05-Energy-Efficiency-inoffices-Motivating-Action-report.pdf

Westminster Sustainable Business Forum (2013) Building Efficiency: Reducing Energy Demand in the Commercial Sector.

http://www.carbonaction2050.com/sites/carbonaction.ciobrebuild.io1dev.com/files/documentattachment/Building $\% 20$ Efficiency $\% 20$ -

\%20Reducing $\% 20$ Energy $\% 20$ Demand $\% 20 \mathrm{in} \% 20$ the $\% 20$ Commercial $\% 20$ Sector.pdf

Yin, R.K. (2003) Case study research: design and methods. 3rd Edition. California: Sage. 